\title{
Supplementary dietary calcium stimulates faecal fat and bile acid excretion, but does not protect against obesity and insulin resistance in C57BL/6J mice
}

\author{
Nicole J. W. de Wit ${ }^{1,2}$, Hanneke Bosch-Vermeulen ${ }^{1,2}$, Els Oosterink ${ }^{1,2}$, Michael Müller ${ }^{1,2 *}$ \\ and Roelof van der Meer ${ }^{1,2}$ \\ ${ }^{1}$ Nutrigenomics Consortium, TI Food and Nutrition, Wageningen, The Netherlands \\ ${ }^{2}$ Nutrition, Metabolism and Genomics Group, Division of Human Nutrition, Wageningen University, PO Box 8129, \\ NL-6700 EV Wageningen, The Netherlands
}

(Received 12 July 2010 - Revised 7 October 2010 - Accepted 14 October 2010 - First published online 23 December 2010)

\section{Abstract}

There is increased interest in the potential protective role of dietary $\mathrm{Ca}$ in the development of metabolic disorders related to the metabolic syndrome. Ca-induced intestinal precipitation of fatty acids and bile acids as well as systemic metabolic effects of Ca on adipose tissue is proposed to play a causal role. In this experiment, we have studied all these aspects to validate the suggested protective effect of Ca supplementation, independent of other dietary changes, on the development of diet-induced obesity and insulin resistance. In our diet intervention study, C57BL/6J mice were fed high-fat diets differing in Ca concentrations $(50 v .150 \mathrm{mmol} / \mathrm{kg})$. Faecal excretion analyses showed an elevated precipitation of intestinal fatty acids (2.3-fold; $P<0.01)$ and bile acids (2-fold; $P<0 \cdot 01)$ on the high-Ca diet. However, this only led to a slight reduction in fat absorption (from 98 to $95 \% ; P<0.01$ ), mainly in the distal small intestine as indicated by gene expression changes. We found no effect on body-weight gain. Lipolysis and lipogenesis-related parameters in adipose tissue also showed no significant changes on the high-Ca diet, indicating no systemic effects of dietary Ca on adiposity. Furthermore, early gene expression changes of intestinal signalling molecules predicted no protective effect of dietary Ca on the development of insulin resistance, which was confirmed by equal values for insulin sensitivity on both diets. Taken together, our data do not support the proposed protective effect of dietary $\mathrm{Ca}$ on the development of obesity and/or insulin resistance, despite a significant increase in faecal excretion of fatty acids and bile acids.

Key words: Dietary calcium: Obesity: Insulin resistance: Differential gene expression

The metabolic syndrome is a cluster of metabolic disorders of which obesity and insulin resistance are considered the major underlying risk factors. Because of the increasing incidence of the metabolic syndrome worldwide, there is increased interest in the potential protective role of dietary $\mathrm{Ca}$ in the development of these metabolic disorders ${ }^{(1,2)}$. Human as well as rodent studies have previously shown that dietary $\mathrm{Ca}$ increases faecal fat excretion by the formation of insoluble Ca-fatty acid soaps in the intestinal lumen ${ }^{(3-6)}$. This Ca-driven lowering of fat absorption is suggested to be a potential dietary intervention to prevent or at least reduce weight gain and adiposity in the current society. However, studies conducted so far do not provide a conclusive answer regarding the effect of Ca supplementation, independent of other changes in the diet (e.g. dairy intake), on faecal fat excretion and its association with a reduction in weight gain or adiposity $(4,7,8)$.

Next to precipitation of fatty acids, dietary $\mathrm{Ca}$ is also able to bind bile acids in the intestinal lumen, thereby increasing faecal bile acid excretion ${ }^{(3,4,9)}$. Interestingly, Kobayashi et al. ${ }^{(10)}$ previously reported that bile acidbinding resins ameliorated diet-induced obesity and insulin resistance, presumably by reducing fat accumulation in the liver and subcutaneous fat. Studies with diabetic patients have also showed that a reduced hepatic lipid accumulation was associated with improved insulin sensitivity and normalised gluconeogenesis ${ }^{(11,12)}$. On the contrary, an increased faecal bile acid excretion may also imply a reduced enterohepatic circulation of bile acids, which might consequently diminish energy expenditure according to Watanabe et al. ${ }^{(13)}$. This might then induce an adverse effect of bile acids on body-weight gain.

A more systemic effect of $\mathrm{Ca}$ on adiposity is suggested by Zemel ${ }^{(14)}$. According to their hypothesis, high dietary $\mathrm{Ca}$ intake is associated with reduced plasma 1,25-vitamin $\mathrm{D}$ and parathyroid hormone (PTH) levels. This would then lead to a decreased $\mathrm{Ca}$ ion influx into adipocytes, eventually resulting in the stimulation of lipolysis and the

Abbreviations: $\mathrm{HCa}$, high-fat, high-Ca diet; LCa, high-fat, low-Ca diet; PTH, parathyroid hormone

*Corresponding author: Professor M. Müller, fax +31 317 483342, email michael.muller@wur.nl 
inhibition of lipogenesis. Ca supplementation trials in human subjects and aP2-agouti transgenic mice conducted by Zemel ${ }^{(14)}$ confirmed an inverse association between Ca and adiposity. This protective effect of $\mathrm{Ca}$ was, however, not found in many other intervention trials ${ }^{(15-18)}$. Thus, conclusive evidence for a systemic effect of dietary $\mathrm{Ca}$ is again lacking.

In the present study, we investigated the effect of Ca supplementation on precipitation of fatty acids and bile acids in the intestinal lumen, as well as the systemic effects of dietary $\mathrm{Ca}$ in relation to the development of the metabolic syndrome. Therefore, we fed C57BL/6J mice a highfat diet with a low $\mathrm{Ca}$ concentration that mimics a habitual Western-type human diet, with a $\mathrm{Ca}$ intake of about $1000 \mathrm{mg} / \mathrm{d}^{(19)}$, or a high-fat diet with a three times higher Ca concentration. In contrast to several related diet intervention studies that have suggested a protective effect of $\mathrm{Ca}$ on obesity and insulin resistance, in the present study, $\mathrm{Ca}$ is the only nutritional compound that differs in concentration between the high-fat diets. Our effects are therefore due solely to dietary $\mathrm{Ca}$. Moreover, the chosen dietary $\mathrm{Ca}$ concentrations in the high-fat diets support extrapolation to the human situation.

\section{Methods}

\section{Animals and diets}

Male C57BL/6J mice were purchased from Harlan (Horst, The Netherlands) and were housed two per cage in the light- and temperature-controlled animal facility of Wageningen University. They had free access to water, and before the diet intervention, they received standard laboratory chow (RMH-B; Arie Blok BV, Woerden, The Netherlands). For all experiments, the institutional and national guidelines for the care and use of animals were followed, and all experiments were approved by the Local Committee for Care and Use of Laboratory Animals at Wageningen University.

After a run-in period of 3 weeks on a low-fat diet, 9- to 12-week-old mice were fed a palm oil-rich, high-fat purified diet with either a low (LCa diet, $50 \mathrm{mmol} / \mathrm{kg}$ ) or high concentration of $\mathrm{Ca}$ ( $\mathrm{HCa}$ diet, $150 \mathrm{mmol} / \mathrm{kg}$ ) for 8 weeks. Dicalcium phosphate and calcium carbonate were the sources of dietary $\mathrm{Ca}$. The diets were composed by Research Diet Services (Wijk bij Duurstede, The Netherlands), and their complete composition is given in the supplementary material (Additional file 1, available online at http://www.journals.cambridge.org/bjn). Note that a low-fat-diet group was also included in this diet intervention study to ensure high-fat diet-induced development of obesity and insulin resistance (data previously published ${ }^{(20)}$ ). During the diet intervention, body weight was recorded weekly. After 2 weeks of intervention, six mice per diet group were killed in the fed state. The small intestines were excised, and the adhering fat and pancreatic tissue were carefully removed. The small intestines were divided into three equal parts along the proximal-to-distal axis (proximal, middle and distal part of the small intestine). Small-intestinal mucosal cells were scraped, snapfrozen in liquid $\mathrm{N}_{2}$ and stored at $-80^{\circ} \mathrm{C}$ until RNA isolation. At week 7, an oral glucose tolerance test was performed; after a $6 \mathrm{~h}$ fast, six mice per diet group received $0.5 \mathrm{ml}$ of a $20 \%$ glucose solution via oral administration, and blood glucose was measured after 15, 30, 45, 60, 90 and 150 min using Accu-Chek blood glucose meters (Roche Diagnostics, Almere, The Netherlands). At week 8, twelve mice per diet group were killed after a $6 \mathrm{~h}$ fast to determine parameters of (hyper)glycaemia in blood and to perform lipid metabolism-related measurements in epididymal white adipose tissue. White adipose tissue was weighed, snap-frozen in liquid $\mathrm{N}_{2}$ and stored at $-80^{\circ} \mathrm{C}$ until RNA isolation. Approximately $1 \mathrm{ml}$ blood was collected in microtubes containing $1.6 \mathrm{mg}$ EDTA (Sarstedt AG \& Co, Nümbrecht, Germany). Plasma was obtained after centrifugation at $11000 \mathrm{~g}$ for $10 \mathrm{~min}$ and frozen at $-80^{\circ} \mathrm{C}$. Before the killing at weeks 2 and 8 , mice were anaesthetised with isoflurane ( $1.5 \%$ in $70 \%$ nitrous oxide/30\% oxygen).

\section{Faecal and plasma analyses}

After 5 weeks of diet intervention, faeces were collected for $48 \mathrm{~h}$. Faeces were lyophilised, weighed and homogenised. Total NEFA and total bile acids in faeces were determined as described previously ${ }^{(3)}$. Appropriate standards and reference samples were assayed simultaneously. The recovery of added standards always exceeded $95 \%$. The absorption efficiency of dietary fat was calculated by subtracting the faecal amounts of fat excreted per $\mathrm{d}$ from the daily fat intake.

Plasma NEFA were assayed enzymatically (NEFA-C kit; Wako Chemicals, Neuss, Germany), and plasma PTH was measured using the Mouse Intact PTH ELISA kit (Immunotopics, Inc., San Clemente, CA, USA). Plasma insulin levels were detected by the Insulin (Mouse) Ultrasensitive EIA (Alpco Diagnostics, Salem, NH, USA) and glycated $\mathrm{Hb}$ (HbA1C) using the A1cNow + test (Metrika BV, Sunnyvale, CA, USA).

\section{RNA isolation}

Total RNA was isolated using TRIzol reagent (Invitrogen, Breda, The Netherlands) according to the manufacturer's instructions. The isolated RNA was further column-purified using the SV total RNA isolation system (Promega, Leiden, The Netherlands). RNA concentration was measured on a NanoDrop ND-1000 UV-Vis spectrophotometer (Isogen, Maarssen, The Netherlands) and analysed on a bioanalyser (Agilent Technologies, Amsterdam, The Netherlands) with 6000 Nano Chips (Agilent Technologies) according to the manufacturer's instructions. 


\section{Complementary DNA synthesis and real-time} quantitative $P C R$

Single-stranded complementary DNA was synthesised from $1 \mu \mathrm{g}$ of total RNA using the Reverse Transcription System (Promega) following the supplier's protocol. Complementary DNA was PCR amplified with Platinum Taq DNA polymerase (all reagents were from Invitrogen). Primer sequences used for real-time quantitative PCR were chosen based on the sequences available in the GenBank database (www.ncbi.nlm.nih.gov), and these are listed in the supplementary material (Additional file 2, available online at http://www.journals.cambridge.org/ bjn). Quantitative PCR were performed using SYBR green (Invitrogen Molecular Probes) and a MyIQ thermal cycler (Bio-Rad Laboratories BV, Veenendaal, The Netherlands). The following thermal cycling conditions were used: $8 \mathrm{~min}$ at $94^{\circ} \mathrm{C}$, followed by forty-five cycles at $94^{\circ} \mathrm{C}$ for $15 \mathrm{~s}$ and $60^{\circ} \mathrm{C}$ for $1 \mathrm{~min}$. PCR were performed in duplicate, and all samples were normalised to cyclophilin A expression.

\section{Microarray hybridisation and analysis}

For each part of the small intestine, total RNA was pooled per diet group ( $n$ 6). RNA was hybridised to Mouse Genome 4302.0 arrays (Affymetrix, Santa Clara, CA, USA). Detailed methods for the labelling and subsequent hybridisations to the arrays are described in the eukaryotic section of the GeneChip Expression Analysis Technical Manual Rev. 3 from Affymetrix, which is available upon request. Arrays were scanned on an Affymetrix GeneChip Scanner 3000 (Affymetrix). Data analysis was performed in MAS 5.0, which is also provided by Affymetrix. To estimate the magnitude and direction of differential gene expression, MAS 5.0 software provides signal log ratios. If the signal log ratio is equal to or greater than zero, fold change is obtained with $2^{\text {(signal } \log \text { ratio) }}$, otherwise $(-1) \times 2^{- \text {(signal } \log \text { ratio) }}$. Based on perfect match and mismatch probes, MAS 5.0 software also calculates the significance of differential gene expression. Array data have been submitted to the Gene Expression Omnibus accession numbers GSE8582 and GSE18581.

\section{Statistical analysis}

Physiological data and quantitative PCR results are reported as means with their standard errors. The differences between the mean values were tested for statistical significance by the independent samples $t$ test (PASW Statistics 17.0 software; SPSS, Inc., Chicago, IL, USA). In short, this means that based on Levene's $t$ test for equality of variance, 'equal variances assumed' or 'equal variances not assumed' $t$ tests were used. $P$ values $<0.05$ are considered to be statistically significant.

\section{Results}

Dietary calcium precipitates fatty acids and bile acids in the gut lumen

First, we determined the capacity of the HCa diet to precipitate dietary fat and bile acids in the small-intestinal lumen (Table 1). We found a significant increase in faecal fat and faecal bile acids on a $\mathrm{HCa}$ diet compared with a LCa diet. To gain more insight into the effect of dietary $\mathrm{Ca}$ on the absorption of fat, we used food intake measurements and faecal excretion data to estimate absolute values and percentages of absorbed dietary fat. Table 1 shows that there is a significant difference in the percentages of fatty acid absorption on a HCa and LCa diet; however, the absolute values are very close together and are not significantly different. Furthermore, the increase in faecal bile acid excretion indicates a reduced reabsorption of bile acids in the small intestine.

\section{The effect of dietary calcium on high-fat diet-induced obesity and adiposity}

To determine the effect of dietary Ca on obesity, we measured food intake and body weight. We found that energy intake on the LCa $(59.8$ (SE 1.7) $\mathrm{kJ} / \mathrm{d}$ ) diet was slightly lower, but was not significantly different from that on the $\mathrm{HCa}$ diet $(61.9$ (SE 1.7) kJ/d). Fig. 1 shows that mice on the LCa and HCa diets gained equal weight during the 8 weeks of diet intervention. However, this did not exclude the possibility that the ratio between fat mass and lean mass differed between mice on the $\mathrm{HCa}$ and the LCa diets. To study the proposed effect of dietary Ca on adipose tissue, we first analysed epididymal fat pads for weight and determined gene expression of the lipogenesis marker fatty acid synthase and the lipolysis marker hormone-sensitive lipase. The weights of epididymal fat pads were not significantly different between the LCa and HCa diets $(2 \cdot 4$ (SE 0.1) and 2.5 (SE 0.1) g, respectively). Also, fatty acid synthase and hormone-sensitive lipase showed no differential gene expression (Fig. 2). Additionally, we measured plasma NEFA and plasma PTH levels to determine $\mathrm{Ca}$-induced changes in the rate of lipolysis. We found no significant differences in plasma NEFA and PTH

Table 1. Faecal fat and bile acid excretion

(Mean values with their standard errors)

\begin{tabular}{|c|c|c|c|c|c|}
\hline & \multicolumn{2}{|c|}{$\mathrm{LCa}$} & \multicolumn{2}{|c|}{$\mathrm{HCa}$} & \multirow[b]{2}{*}{$P$} \\
\hline & Mean & SE & Mean & SE & \\
\hline Dietary fat intake $(\mathrm{mg} / \mathrm{d})$ & $747 \cdot 1$ & $36 \cdot 0$ & $748 \cdot 8$ & $15 \cdot 9$ & 0.96 \\
\hline Faecal fat $(\mathrm{mg} / \mathrm{d})$ & 17.9 & 1.6 & $41 \cdot 2$ & 3.7 & $<0.01$ \\
\hline Fat absorption $(\mathrm{mg} / \mathrm{d})$ & $729 \cdot 2$ & 34.9 & $707 \cdot 7$ & 13.4 & 0.49 \\
\hline $\begin{array}{l}\text { Fat absorption } \\
\text { (\% of daily intake) }\end{array}$ & $97 \cdot 6$ & 0.2 & $94 \cdot 6$ & 0.4 & $<0.01$ \\
\hline Faecal bile acids $(\mu \mathrm{mol} / \mathrm{d})$ & 1.4 & 0.1 & $2 \cdot 8$ & 0.3 & $<0.01$ \\
\hline
\end{tabular}

LCa, high-fat, low-Ca diet; HCa, high-fat, high-Ca diet. 


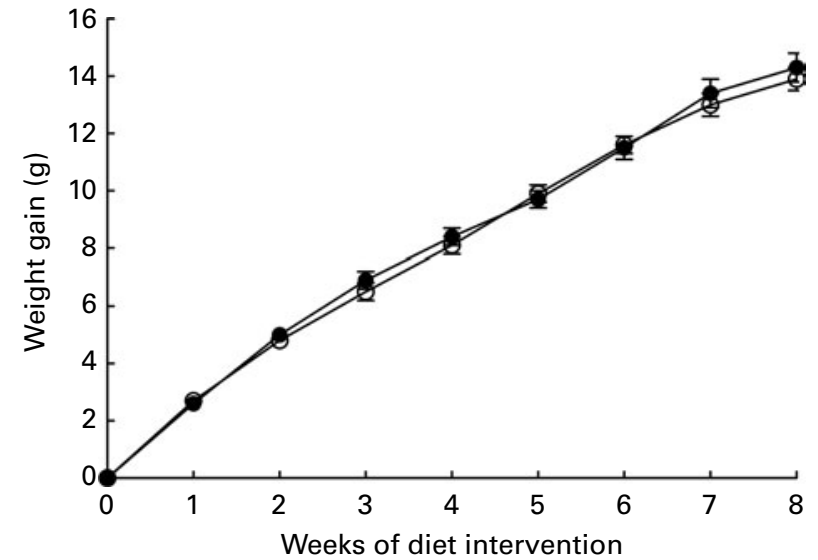

Fig. 1. Body-weight gain. Body weight of C57BL/6J mice was recorded weekly during a diet intervention of 8 weeks. Values are means, with standard errors represented by vertical lines. $\mathrm{LCa}$, high-fat, low-Ca diet $(-\mathrm{O}-)$; $\mathrm{HCa}$, high-fat, high-Ca diet (-๑-).

after 8 weeks of LCa and HCa diet intervention (Table 2). Together, our data indicate that dietary $\mathrm{Ca}$ has no effect on fat-induced obesity and adiposity.

\section{Dietary calcium-induced changes in small-intestinal gene expression}

In a previous study, we found that dietary fat-induced gene expression changes in the small intestine could already be detected after 2 weeks of diet intervention ${ }^{(20)}$. Therefore, we now also performed microarray analysis of mucosal scrapings after 2 weeks of LCa and HCa diet intervention to determine whether the effects of dietary Ca on precipitation, and therefore also (re)absorption of fatty acids and bile acids, modulate gene expression (Table 3). For lipid metabolism-related genes, we found hardly any changes in the proximal and middle part of the small intestine, where most of the fatty acids are usually absorbed. In the distal part of the small intestine, however, dietary Ca

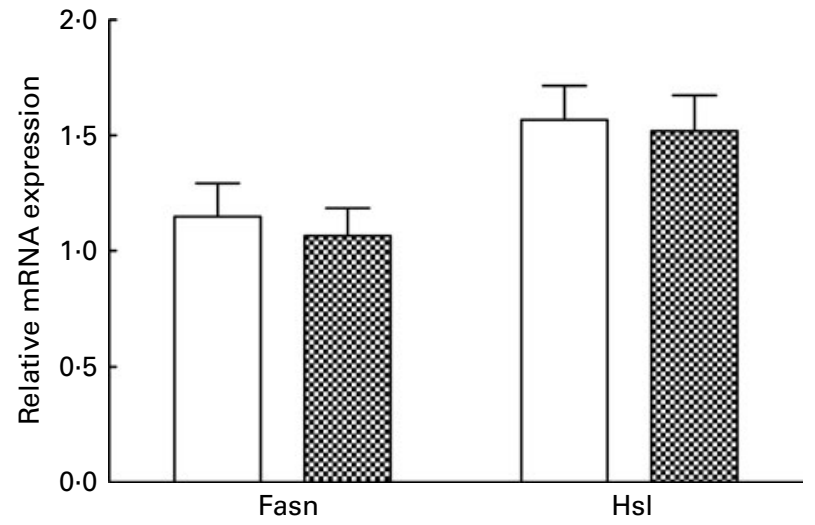

Fig. 2. Fatty acid synthase (Fasn) and hormone-sensitive lipase (Hsl) expression in epididymal white adipose tissue. Gene expression in epididymal white adipose tissue of the lipogenesis marker Fasn and lipolysis marker Hsl after 8 weeks of high-fat, low-Ca diet (LCa, $\square$ ) and high-fat, high-Ca diet ( $\mathrm{HCa}$, ⿴) intervention, analysed by quantitative PCR. Values are means, with standard errors represented by vertical bars.
Table 2. Fasting plasma concentration of lipolysis-related markers (Mean values with their standard errors)

\begin{tabular}{lrrrrrr}
\hline & \multicolumn{2}{c}{ LCa } & & \multicolumn{2}{c}{$\mathrm{HCa}$} & \\
\cline { 2 - 3 } & Mean & SE & & Mean & SE & $P$ \\
\hline NEFA $(\mu \mathrm{m})$ & 211.7 & 4.4 & & 208.4 & 2.5 & 0.48 \\
Intact PTH $(\mathrm{pg} / \mathrm{ml})$ & 83.1 & 7.3 & 86.8 & 16.9 & 0.85 \\
\hline
\end{tabular}

LCa, high-fat, low-Ca diet; HCa, high-fat, high-Ca diet; PTH, parathyroid hormone.

induced a decrease in the expression of genes, which are key regulators in the catabolism of fatty acids (Cpt1a, $\beta$-oxidation; Cyp4a10, $\omega$-oxidation; Hmgcs2, ketogenesis). No or minimal gene expression changes could be determined in fatty acid transport and chylomicron synthesis. As expected, the most pronounced changes in gene expression related to bile acid metabolism were seen in the distal part of the small intestine, as this is where reabsorption occurs. We found a small down-regulation of Fgf15 and an up-regulation in apical (Slc10a2) and basolateral (Ostb) bile acid transporters.

According to the hypothesis of Kobayashi et al. ${ }^{(10)}$, binding of bile acids in the intestinal lumen might prevent the development of insulin resistance. To get a first impression whether the $\mathrm{Ca}$-induced precipitation of bile acids that we found in the present study could indeed prevent the development of insulin resistance, we determined gene expression of the intestinal signalling molecules Angptl4, Igfbp3, Mif and Il18. An up-regulation of Angptl4, Igfbp3 and Mif and a down-regulation of Il18 were previously found to be associated with the onset of dietary fat-induced insulin resistance ${ }^{(20)}$. In this study, we found a dietary Ca-induced up-regulation of Angplt4, Mif and I118 and no differential gene expression of Igfbp3, after 2 weeks of diet intervention.

\section{The effect of dietary calcium on high-fat diet-induced insulin resistance}

To ascertain that the early Ca-induced gene expression changes in intestinal signalling molecules precede the development of insulin resistance, we performed an oral glucose tolerance test after 7 weeks of diet intervention (Fig. 3). We found no significant difference in blood glucose clearance between the diets, although the area under the curve was slightly higher on the $\mathrm{HCa}$ diet $(P=0 \cdot 1)$. Additionally, at the end of the diet intervention, we measured the percentage of glycated $\mathrm{Hb}$ (HbA1C) in the plasma and calculated the homeostasis model assessment for insulin resistance index from fasting glucose and fasting insulin levels (fasting glucose $\times$ fasting insulin/22.5) (Table 4). We also found no significant differences for these parameters between the LCa and HCa diets, but together with the oral glucose tolerance test data, the present results suggest a slightly compromised insulin sensitivity on the HCa diet. This is in accordance with the early gene expression changes of Angptl4 and Mif. 
Table 3. Diet-induced differential gene expression in the small-intestinal mucosa

\begin{tabular}{|c|c|c|c|c|}
\hline Gene name & Symbol & Proximal SI* & Middle $\mathrm{SI}^{*}$ & Distal SI \\
\hline \multicolumn{5}{|l|}{ Lipid metabolism } \\
\hline \multicolumn{5}{|l|}{ Fatty acid transport } \\
\hline Solute carrier family 27, member 2 & Slc27a2 & NC & NC & NC \\
\hline \multicolumn{5}{|l|}{ Fatty acid catabolism } \\
\hline Carnitine palmitoyltransferase $1 \mathrm{a}$ & Cpt1a & NC & NC & -1.36 \\
\hline Cytochrome P450, family 4 subfamily a, polypeptide 10 & Сyp4a10 & NC & NC & -1.48 \\
\hline 3-Hydroxy-3-methylglutaryl-CoA synthase 2 & Hmgcs2 & 1.29 & 1.35 & -1.36 \\
\hline \multicolumn{5}{|l|}{ Chylomicron synthesis } \\
\hline apo B & Apob & NC & NC & NC \\
\hline apo C-II & Apoc2 & NC & NC & 1.26 \\
\hline apo C-III & Apoc3 & NC & NC & NC \\
\hline Microsomal TAG transfer protein & Mttp & NC & NC & NC \\
\hline \multicolumn{5}{|l|}{ Bile acid metabolism } \\
\hline \multicolumn{5}{|l|}{ Bile acid transport } \\
\hline Ileal bile acid-binding protein & Ibabp, Fabp6 & A & -2.00 & NC \\
\hline Organic solute transporter $\beta$ & Ostb & NC & NC & 1.33 \\
\hline Solute carrier family 10, member 2 (Asbt) & Slc10a2 & A & A & 1.84 \\
\hline \multicolumn{5}{|l|}{ Negative feedback hepatic bile acid synthesis } \\
\hline Fibroblast growth factor 15 & Fgf15 & A & A & $-1 \cdot 16$ \\
\hline \multicolumn{5}{|l|}{ Secreted (signalling) molecules } \\
\hline Angiopoietin-like 4 & Angpt14 & 1.55 & 1.59 & 1.34 \\
\hline Insulin-like growth factor-binding protein 3 & Igfbp3 & NC & NC & NC \\
\hline IL-18 & $\| 18$ & NC & NC & 1.67 \\
\hline Macrophage migration inhibitory factor & Mif & NC & $1 \cdot 15$ & 1.45 \\
\hline
\end{tabular}

SI, small intestine; NC, no change; A, absent.

* Differential gene expression is indicated by fold changes of $\mathrm{HCa} / \mathrm{LCa}$. Positive and negative numbers indicate a significant up- and downregulation, respectively.

\section{Discussion}

In the present study, we clearly showed that dietary $\mathrm{Ca}$ precipitates fatty acids and bile acids in the small intestinal lumen and thereby increases the faecal excretion of both components. For fatty acids, we calculated that this increase in faecal excretion on the $\mathrm{HCa}$ diet leads to a slight decrease in the percentage of dietary fat that is absorbed. This change in fat absorption is most pronounced in the distal part of the small intestine based on our gene expression data. Nevertheless, the absolute values of absorbed dietary fat on a HCa and LCa diet are

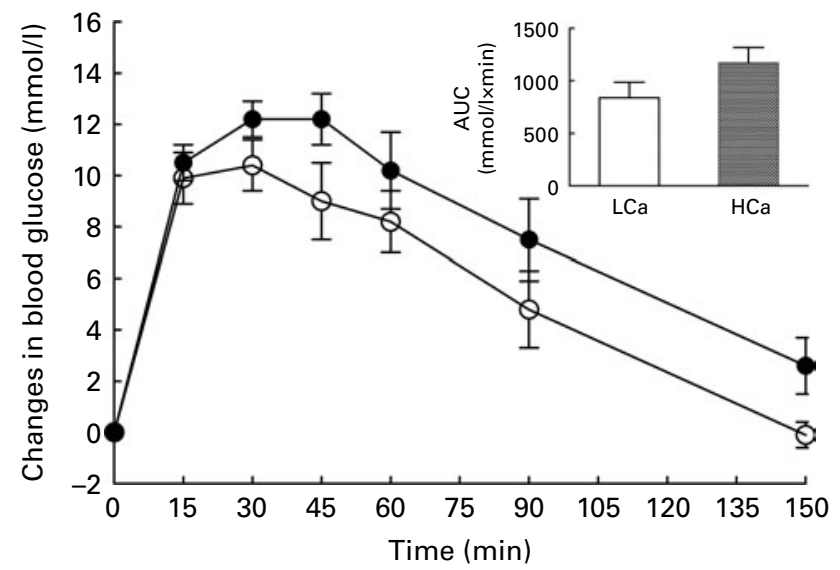

Fig. 3. Oral glucose tolerance test. An oral glucose tolerance test was performed after 7 weeks of diet intervention. After oral administration of $100 \mathrm{mg}$ glucose, blood glucose levels were monitored for $150 \mathrm{~min}$. The changes in blood glucose levels and the area under the curve (AUC) were calculated (see inset; $P=0 \cdot 1)$. Values are means, with standard errors represented by vertical lines. LCa, high-fat, low-Ca diet (-O-); HCa, high-fat, high-Ca diet (-๑-). still very similar and are not significantly changed by dietary $\mathrm{Ca}$. This could explain why we do not see a lower weight gain on the $\mathrm{HCa}$ diet, which contrasts with the hypothesis proposed by Astrup and co-workers ${ }^{(4,8)}$.

The dietary Ca-induced down-regulation of Fgf15, a target gene of the nuclear bile acid receptor farnasoid $\mathrm{X}$ receptor ${ }^{(21)}$, suggests a decreased bile acid reabsorption on a HCa diet. The decreased expression of Fgf15 is probably a compensatory mechanism for the faecal loss of bile acids on a $\mathrm{HCa}$ diet, as reduced Fgf15 signalling triggers the liver to increase the bile acid synthesis ${ }^{(22)}$. This is in accordance with other studies that reported an increase in biliary bile acid secretion upon increased faecal excretion of bile acids ${ }^{(10,23)}$. Kobayashi et al. ${ }^{(10)}$ reported that an increase in bile acid synthesis, which is induced by bile acid-binding resin, results in changes in lipid and glucose metabolism which are related to reduced obesity and insulin resistance. However, as we found no effect of dietary $\mathrm{Ca}$ on fat-induced obesity and insulin resistance,

Table 4. Physiological parameters that are (in)directly associated with insulin sensitivity

(Mean values with their standard errors)

\begin{tabular}{lrrrrrr}
\hline & \multicolumn{2}{c}{ LCa } & & \multicolumn{2}{c}{ HCa } & \\
\cline { 2 - 3 } & Mean & SE & & Mean & SE & $P$ \\
\hline HbA1C (\%) & 4.6 & 0.1 & & 4.7 & 0.1 & 0.23 \\
Fasting glucose (mmol/l) & 10.3 & 0.3 & & 10.3 & 0.3 & 0.94 \\
Fasting insulin (pmol/l) & 249.3 & 42.4 & & 218.3 & 30.9 & 0.56 \\
HOMA-IR & 17.0 & 3.6 & & 14.7 & 2.3 & 0.57 \\
\hline
\end{tabular}

LCa, high-fat, low-Ca diet; $\mathrm{HCa}$, high-fat, high-Ca diet; $\mathrm{HbA1C}$, glycated $\mathrm{Hb}$; HOMA-IR, homeostasis model assessment for insulin resistance. 
we conclude that the effects of bile acid-binding resins on these metabolic disorders cannot be extrapolated to dietary $\mathrm{Ca}$. The unexpected up-regulation of bile acid transporters Slc10a2 and Ostb that we found in the present study can be explained by the relative increase of hydrophilic bile acids in the intestinal lumen on the HCa diet, as Ca predominantly precipitates hydrophobic bile acids ${ }^{(24)}$. Asamoto et $a l^{(25)}$ previously found that hydrophilic bile acids are associated with an induction of bile acid transporters. The up-regulation of Slc10a2 and Ostb also implies that the Cainduced increase in faecal excretion of bile acids does not necessarily lead to a reduced enterohepatic circulation ${ }^{(26)}$ and a consequent reduction in energy expenditure ${ }^{(13)}$.

In contrast to the hypothesis of $\mathrm{Zemel}^{(14,27)}$, the low $(50 \mathrm{mmol} / \mathrm{kg}, 0.2 \%) v$. high Ca concentrations $(150 \mathrm{mmol} /$ $\mathrm{kg}, 0.6 \%)$ in our high-fat diets did not induce differences in body-weight gain and adiposity after an 8-week diet intervention. A similar result for body weight was recently described by Zhang \& Tordoff ${ }^{(17)}$ using dietary Ca concentrations that were highly comparable to the ones we used in the present study as well as higher Ca concentrations $(1.8 \%)$, all of which were not effective in the regulation of body weight. One might argue that the Ca concentration in the LCa diets (0.2\%) used in Zhang's and the present study was still adequate for optimal metabolic functioning and that therefore no effects on adiposity could be found. Our LCa diet mimics a human Ca intake of $1000 \mathrm{mg} / \mathrm{d}$, assuming a daily food intake of $500 \mathrm{~g}$ dry weight. The results of the present study are in line with recent human studies, in which obese adults were supplemented with $1500 \mathrm{mg} \mathrm{Ca} / \mathrm{d}$ for 3 months or 2 years, showing no effect of dietary $\mathrm{Ca}$ on body weight, lipid oxidation or lipolysis $^{(16,28)}$. Note that in these studies, subjects with a habitual $\mathrm{Ca}$ intake exceeding $850 \mathrm{mg} / \mathrm{d}$ or even $700 \mathrm{mg} / \mathrm{d}$ were excluded. Zemel et al., who used $\mathrm{Ca}$ concentrations in the diets ranging from 0.4 to $2 \cdot 4 \%$, based their hypothesis of dietary Ca-induced inhibition of lipogenesis and stimulation of lipolysis mainly on aP2-agouti transgenic mice studies. They found a dietary Ca-induced reduction in body weight ${ }^{(29)}$. However, this transgenic mouse model of diet-induced obesity is probably not very representative for effects in wild-type mice. Parra et al. ${ }^{(30)} \mathrm{did}$ report an anti-obesity effect of dairy $\mathrm{Ca}$ in wild-type $\mathrm{C} 57 \mathrm{BL} / 6 \mathrm{~J}$ mice. However, similar to the studies in aP2-agouti transgenic mice, the compared diets did not differ only in $\mathrm{Ca}$ content, but also contained variations in casein and sucrose concentrations. These additional dietary changes might very well also have an effect on the regulation of body weight $^{(31,32)}$. Moreover, in contrast to the present study, a substantial amount of $\mathrm{Ca}$ in their diets was derived from dairy products. There is growing evidence that other components in dairy products, such as medium-chain fatty acids, and dairy proteins work synergistically with $\mathrm{Ca}$ to alter lipid metabolism ${ }^{(1,18,33,34)}$.

After 2 weeks of diet intervention, the gene expression data of intestinal signalling molecules Angptl4, Igfbp3 and Mif already indicated no preventive effect of dietary $\mathrm{Ca}$ on the development of insulin resistance. Only the up-regulation of Il18 suggested a preventive effect of dietary $\mathrm{Ca}$-induced precipitation of bile acids on the development of insulin resistance. After 7 and 8 weeks of diet intervention, we measured multiple physiological parameters that are directly or indirectly associated with insulin sensitivity. Next to an oral glucose tolerance test and HbA1C, we measured fasting glucose and fasting insulin to calculate the homeostasis model assessment for insulin resistance index. The homeostasis model assessment for insulin resistance index is a commonly used measure of insulin sensitivity in rodent studies; however, note that it should be interpreted with caution as it was never validated for animal models. Surprisingly, both gene expression data and physiological parameters suggest even a slightly worsened insulin sensitivity on the $\mathrm{HCa}$ diet. In accordance with the present results, Hoppe et $a l{ }^{(35)}$ previously reported that a short-term high milk intake leads to increased insulin resistance. A possible explanation for this impairment in insulin sensitivity on a high dietary $\mathrm{Ca}$ intake might be a lowered absorption of $\mathrm{Mg}$ due to the formation of an insoluble calciummagnesium-phosphate complex in the intestinal lumen ${ }^{(36)}$. Changes in $\mathrm{Mg}$ intake were previously linked to insulin resistance ${ }^{(37,38)}$. However, further research is necessary to gain more insight into this phenomenon.

In conclusion, the present study showed no protective effect of dietary $\mathrm{Ca}$ on the development of fat-induced obesity and/or insulin resistance, despite the significant increase in faecal excretion of fatty acids and bile acids on a HCa diet. Therefore, the present results do not support hypotheses which suggest that $\mathrm{Ca}$ by itself has the capacity to regulate body weight, adiposity and insulin sensitivity.

\section{Acknowledgements}

The present study was funded by the Netherlands Genomics Initiative. The authors declare that there are no conflicts of interest. N. J. W. d. W., M. M. and R. v. d. M. designed the research; N. J. W. d. W., H. B.-V. and E. O. conducted the research; N. J. W. d. W. wrote the manuscript; N. J. W. d. W. and R. v. d. M. had primary responsibility for the final content. All authors read and approved the final manuscript. N. J. W. d. W. thanks Janneke de Wilde, Bert Weijers and Rene Bakker for their excellent and stimulating technical assistance with the animal studies.

\section{References}

1. van Meijl LEC, Vrolix R \& Mensink RP (2008) Dairy product consumption and the metabolic syndrome. Nutr Res Rev 21, 148-157. 
2. Major GC, Chaput JP, Ledoux M, et al. (2008) Recent developments in calcium-related obesity research. Obes Rev 9, 428-445.

3. Govers MJAP, Termont DSML \& Van der Meer R (1994) Mechanism of the antiproliferative effect of milk mineral and other calcium supplements on colonic epithelium. Cancer Res 54, 95-100.

4. Bendsen NT, Hother AL, Jensen SK, et al. (2008) Effect of dairy calcium on fecal fat excretion: a randomized crossover trial. Int J Obes 32, 1816-1824.

5. Pilvi TK, Korpela R, Huttunen M, et al. (2007) Highcalcium diet with whey protein attenuates body-weight gain in high-fat-fed C57Bl/6J mice. Br J Nutr 98, 900-907.

6. Papakonstantinou E, Flatt WP, Huth PJ, et al. (2003) High dietary calcium reduces body fat content, digestibility of fat, and serum vitamin D in rats. Obes Res 11, 387-394.

7. Boon N, Hul GBJ, Stegen JHCH, et al. (2007) An intervention study of the effects of calcium intake on faecal fat excretion, energy metabolism and adipose tissue mRNA expression of lipid-metabolism related proteins. Int J Obes 31, 1704-1712.

8. Christensen R, Lorenzen JK, Svith CR, et al. (2009) Effect of calcium from dairy and dietary supplements on faecal fat excretion: a meta-analysis of randomized controlled trials. Obes Rev 10, 475-486.

9. Van der Meer R, Welberg JW, Kuipers F, et al. (1990) Effects of supplemental dietary calcium on the intestinal association of calcium, phosphate, and bile acids. Gastroenterology 99, 1653-1659.

10. Kobayashi M, Ikegami H, Fujisawa T, et al. (2007) Prevention and treatment of obesity, insulin resistance, and diabetes by bile acid-binding resin. Diabetes 56, 239-247.

11. Petersen KF, Dufour S, Befroy D, et al. (2005) Reversal of nonalcoholic hepatic steatosis, hepatic insulin resistance, and hyperglycemia by moderate weight reduction in patients with type 2 diabetes. Diabetes 54, 603-608.

12. Tiikkainen M, Bergholm R, Vehkavaara S, et al. (2003) Effects of identical weight loss on body composition and features of insulin resistance in obese women with high and low liver fat content. Diabetes 52, 701-707.

13. Watanabe M, Houten SM, Mataki C, et al. (2006) Bile acids induce energy expenditure by promoting intracellular thyroid hormone activation. Nature 439, 484-489.

14. Zemel MB (2005) The role of dairy foods in weight management. J Am Coll Nutr 24, 537S-546S.

15. Boon N, Hul GBJ, Viguerie N, et al. (2005) Effects of 3 diets with various calcium contents on 24-h energy expenditure, fat oxidation, and adipose tissue message RNA expression of lipid metabolism-related proteins. Am J Clin Nutr 82, $1244-1252$.

16. Sampath V, Havel PJ \& King JC (2008) Calcium supplementation does not alter lipid oxidation or lipolysis in overweight/ obese women. Obesity (Silver Spring) 16, 2400-2404.

17. Zhang Q \& Tordoff MG (2004) No effect of dietary calcium on body weight of lean and obese mice and rats. $A m J$ Physiol Regul Integr Comp Physiol 286, R669-R677.

18. Schrager S (2005) Dietary calcium intake and obesity. J Am Board Fam Pract 18, 205-210.

19. Newmark HL (1987) Nutrient density: an important and useful tool for laboratory animal studies. Carcinogenesis $\mathbf{8}$, 871-873.

20. de Wit NJ, Bosch-Vermeulen H, de Groot PJ, et al. (2008) The role of the small intestine in the development of dietary fat-induced obesity and insulin resistance in $\mathrm{C} 57 \mathrm{BL} / 6 \mathrm{~J}$ mice. BMC Med Genomics 1, 14.

21. Makishima M, Okamoto AY, Repa JJ, et al. (1999) Identification of a nuclear receptor for bile acids. Science 284, 1362-1365.

22. Jung D, Inagaki T, Gerard RD, et al. (2007) FXR agonists and FGF15 reduce fecal bile acid excretion in a mouse model of bile acid malabsorption. J Lipid Res $\mathbf{4 8}$, 2693-2700.

23. Moutafis CD, Simons LA, Myant NB, et al. (1977) The effect of cholestyramine on the faecal excretion of bile acids and neutral steroids in familial hypercholesterolaemia. Atherosclerosis 26, 329-334.

24. Govers MJAP, Termont DSML, Lapre JA, et al. (1996) Calcium in milk products precipitates intestinal fatty acids and secondary bile acids and thus inhibits colonic cytotoxicity in humans. Cancer Res 56, 3270-3275.

25. Asamoto Y, Tazuma S, Ochi H, et al. (2001) Bile-salt hydrophobicity is a key factor regulating rat liver plasmamembrane communication: relation to bilayer structure, fluidity and transporter expression and function. Biochem $J$ 359, 605-610.

26. Dawson PA, Haywood J, Craddock AL, et al. (2003) Targeted deletion of the ileal bile acid transporter eliminates enterohepatic cycling of bile acids in mice. $J$ Biol Chem 278 , 33920-33927.

27. Zemel MB (2003) Mechanisms of dairy modulation of adiposity. J Nutr 133, 252S-256S.

28. Yanovski JA, Parikh SJ, Yanoff LB, et al. (2009) Effects of calcium supplementation on body weight and adiposity in overweight and obese adults. Ann Intern Med 150, $821-829$

29. Shi H, Dirienzo D \& Zemel MB (2001) Effects of dietary calcium on adipocyte lipid metabolism and body weight regulation in energy-restricted aP2-agouti transgenic mice. FASEB J 15, 291-293.

30. Parra P, Bruni G, Palou A, et al. (2008) Dietary calcium attenuation of body fat gain during high-fat feeding in mice. J Nutr Biochem 19, 109-117.

31. Elliott SS, Keim NL, Stern JS, et al. (2002) Fructose, weight gain, and the insulin resistance syndrome. Am J Clin Nutr 76, 911-922.

32. Westerterp-Plantenga MS, Nieuwenhuizen A, Tome D, et al. (2009) Dietary protein, weight loss, and weight maintenance. Ann Rev Nutr 29, 21-41.

33. Shah NP (2000) Effects of milk-derived bioactives: an overview. Br J Nutr 84, Suppl. 1, S3-S10.

34. Pfeuffer M \& Schrezenmeir J (2007) Milk and the metabolic syndrome. Obes Rev 8, 109-118.

35. Hoppe C, Molgaard C, Vaag A, et al. (2004) High intakes of milk, but not meat, increase s-insulin and insulin resistance in 8-year-old boys. Eur J Clin Nutr 59, 393-398.

36. Brink EJ, Beynen AC, Dekker PR, et al. (1992) Interaction of calcium and phosphate decreases ileal magnesium solubility and apparent magnesium absorption in rats. $J$ Nutr $\mathbf{1 2 2}$, $580-586$

37. He K, Liu K, Daviglus ML, et al. (2006) Magnesium intake and incidence of metabolic syndrome among young adults. Circulation 113, 1675-1682.

38. Barbagallo M \& Dominguez LJ (2007) Magnesium metabolism in type 2 diabetes mellitus, metabolic syndrome and insulin resistance. Arch Biochem Biophys 458, 40-47. 